\title{
Poverty, Food Insecurity, and Nutritional Outcomes in Children and Adults*
}

\author{
Jayanta Bhattacharya \\ Assistant Professor, Stanford Medical School \\ Center for Primary Care and Outcomes Research \\ Janet Currie \\ Professor, Department of Economics \\ University of California at Los Angeles and NBER \\ Steven Haider \\ Assistant Professor, Department of Economics \\ Michigan State University
}

JEL: I12, I32

\begin{abstract}
Using data from the National Health and Nutrition Examination Survey, we examine the relationship between nutritional status, poverty, and food insecurity for household members of various ages. Our most striking result is that, while poverty is predictive of poor nutrition among preschool children, food insecurity does not provide any additional predictive power for this age group. Among school age children, neither poverty nor food insecurity is associated with nutritional outcomes, while among adults and the elderly, both food insecurity and poverty are predictive. These results suggest that researchers should be cautious about assuming connections between food insecurity and nutritional outcomes, particularly among children.
\end{abstract}

*Please send correspondence to Janet Currie, Dept. of Economics, UCLA, 405 Hilgard Ave., Los Angeles CA 90095-1477, currie@simba.sscnet.ucla.edu. Bhattacharya and Haider gratefully acknowledge the financial support from the USDA/Institute for Research on Poverty Small Grants Program. The authors thank Alison Jacknowitz for superb research assistance and are grateful for the helpful comments from the participants at the USDA Small Grants Workshop in Madison, Wisconsin; the USDA Small Grants Conference in Washington, DC; the Dartmouth Labor Seminar; and the University of Maryland Demography of Inequality Seminar. All opinions expressed herein are solely those of the authors. 


\section{INTRODUCTION}

The U.S. Government has been producing official poverty estimates for over 35 years. The intent of the poverty measure is to identify households with "inadequate resources to obtain basic living needs,” where basic needs are considered to be food, clothing, and shelter (Citro and Michael, 1995). Poverty in the United States is determined by comparing a family's actual income to a poverty line that was originally a multiple of the amount of income deemed necessary to purchase a "thrifty food basket" (Orshansky, 1965). However, in recent years, the idea that official poverty rates measure actual physical deprivation has been criticized. For example, Slesnick (1993) finds that consumption-based measures of poverty are substantially lower than those based on income, and Jencks and Mayer (1989) argue that the official poverty measure does a poor job of measuring material hardship. A recent National Academy of Sciences report concluded that the official poverty measure is flawed and made numerous recommendations for improving it (Citro and Michael, 1995). ${ }^{2}$

Partially in response to criticisms of the poverty measure, the government has also collected more direct measures of material hardship such as the food insecurity measures. These measures are widely used to measure "hunger" in America. This paper examines the extent to which poverty and food insecurity are predictive of several measures of nutritional status. We use a unique dataset, the National Health and Nutrition Examination Survey III (NHANES III). In addition to the dietary recall information collected in other data sets, NHANES III conducts a physical exam of the participants, collecting weight and height and analyzing their blood. This examination data provides measures of nutritional status for individuals of all ages that is not subject to recall or proxy bias. Thus, these data allow us to more

\footnotetext{
${ }^{2}$ In earlier drafts of this paper, we constructed alternative poverty measures based on some of the suggestions in Citro and Michael (1995). However, not all of these suggestions can be implemented given the data in NHANES III, and the correlation between the alternative measures and the official poverty measure is very high. Thus, we do not consider additional measures in this paper.
} 
precisely examine the way in which correlations between poverty, food insecurity, and nutritional outcomes vary by age. This last point is particularly valuable given that many anti-hunger programs (such as school nutrition programs) target people of particular ages.

We find that once poverty is controlled for, the food insecurity questions are predictive of the nutritional outcomes of older household members, but are not consistently related to the diets of children. In contrast, poverty predicts nutritional outcomes among both preschoolers and adults. Moreover, there are interesting differences between racial and ethnic groups, with the effects of poverty being generally greater for black and Hispanic children than for whites, while the effects of food insecurity are largest for the Hispanic elderly.

We note one important caveat to our conclusions from the outset. Most studies that examine food insecurity use a summary measure based on a series of questions. The NHANES III does not contain the entire series of questions, so a direct examination of the summary measure cannot be undertaken. However, the questions that are available in NHANES III are very similar to those available in the CPS, and these questions are very highly correlated with the summary measures. Thus, we interpret our results to be a strong indicator of what would be obtained if the entire set of food insecurity questions were available in NHANES III.

The rest of the paper is organized as follows. We describe the data set in Section 2 and the construction of variables in Section 3; the Appendix gives significantly more details about variable construction. Section 4 provides a regression analysis of the relationship between the variables and measures of nutritional status. We end with a discussion and conclusion in Section 5.

\section{HUNGER, NUTRITIONAL DEPRIVATION, AND FOOD INSECURITY}

There is some confusion in the literature about what is meant by "hunger". Writing in the Journal of the American Dietetic Association, Lenhart and Read (1989, page 1269) state that hunger is “a 
condition resulting from chronic under-consumption of food and/or nutritious food products”. However, frank starvation is very rare in the United States. The 1984 President's Task Force on Food Assistance chaired by Clayton LaForce was established to look into other issues of concern, including reports of overwhelmed food banks, people going without food for days at a time, and seniors eating pet food. The commission concluded however, that hunger was not a well-defined concept, and that it was therefore difficult to measure given that actual malnutrition was rare (President's Task Force on Food Assistance, 1984).

Hence, in the 1990s, the United States Department of Agriculture (USDA) convened expert panels on hunger measurement and subsequently developed a battery of survey questions designed to measure "food insecurity". ${ }^{3}$ These questions (which are reproduced in Appendix Table A1) ask about whether the household was worried about having the money to pay for food, whether there were times that the household was without food, and about whether specific household members went without food.

While it is clear that food insecurity is intended to measure something conceptually different than nutritional deprivation, many authors argue that a strong connection remains. For example, Dietz and Trowbridge (1990, page 917) write that "Hunger is a recurrent, involuntary lack of access to food. Hunger may produce malnutrition over time”. Similarly, the Food Research and Action Committee writes that "While starvation seldom occurs in this country, children and adults do go hungry and chronic mild undernutrition does occur when financial resources are low. The mental and physical changes that accompany inadequate food intakes can have harmful effects on learning, development, productivity, physical and psychological health, and family life”

(http://www.frac.org/html/hunger_in_the_us/hunger_index.html). The clear import of these statements is that one of the reasons for interest in food insecurity is its potential relationship to actual nutritional deprivation.

\footnotetext{
${ }^{3}$ For a description of the process and the resulting scale, see Andrews, Bickel and Carlson (1998) and Hamilton et al. (1997).
} 
The instrument developed by the USDA has been administered annually since 1995 as part of the Current Population Survey (CPS), and it has been adopted (in part) by many other surveys. ${ }^{4}$ It has become the basis for official estimates of the number of hungry people in the U.S. Moreover, numerous research papers have used these new questions to analyze a variety of topics (for recent examples, see Alaimo and Olson, 2001; Borjas, 2002; Kowaleski-Jones and Dunifon, 2001; Siefert et al., 2001; Weinreb et al., 2002; and Winship and Jencks, 2002; for a detailed bibliography, see Bickel et al., 2000).

The benefit of the CPS food insecurity questions is that they are relatively inexpensive to ask and are asked more frequently and consistently than the direct measures of nutritional status collected in episodic surveys such as the Continuing Surveys of Food Intakes by Individuals (CSFII) and the NHANES. For example, Rose et al. (1995) point out that it was previously difficult to track food security over time because of differences in survey methods between waves of these surveys, and Currie and Bhattacharya (2001) found that for adolescents, BMI was the only one of a number of nutritional measures that could be consistently followed over waves of the NHANES.

Several studies have begun the process of examining the validity of the food insecurity questions. These studies have examined how the questions are correlated among themselves (i.e., their internal validity) and how the questions are correlated with demographic characteristics, household characteristics, and measures of outcomes (i.e., their external validity). ${ }^{5}$ Generally, these studies find that food insecurity questions are correlated in expected ways with both internal and external factors. For example, relying on the Continuing Survey of Food Intake by Individuals, Rose (1999) found that, in households reporting insufficient food, most household members took in significantly less of most

${ }^{4}$ For example, some of the food security questions are included in the Panel Study of Income Dynamics, the Survey of Program Dynamics, the Health and Retirement Surveys, the NHANES III (which we use here), the Los Angeles Family and Neighborhood Survey, and welfare attrition studies in Michigan and California.

${ }^{5}$ For a useful discussion of these studies, see the 1999 Supplement "Symposium: Advances in Measuring Food Insecurity and Hunger in the U.S.” to the Journal of Nutrition. Other validation studies include Derrickson et al. (2000), Hamilton et al. (1997), and Rose and Oliveria (1997). 
vitamins and minerals than did member of other households. One exception was that preschoolers in food insecure households did not suffer from low consumption.

Dixon et al. (2001) use the NHANES III data to examine the relationship between food insecurity, dietary intakes of many specific foods, and serum nutrients levels. However, unlike our study, they only examine adults, and do not compare the predictive power of food insecurity and poverty measures. They also focus on comparisons of means, and conclude, for example, that mean levels of serum nutrients are within the normal range for both food insecure and non-food insecure adults. Finally, we also extend the literature by presenting separate estimates by race and ethnicity.

\section{DATA}

We rely on data from the National Health and Nutrition Examination Survey III for our analysis. This national survey was conducted between October 1988 and October 1994 and included nearly 34,000 respondents, aged 2 months and older. The survey over-sampled blacks, Mexican Americans, younger children, and older persons to assure adequate representation and includes weights to make the sample nationally representative.

NHANES III collects information in the usual survey domains, including demographics (e.g., age and gender), income (e.g., labor income and government program participation), self-reported health (e.g., diseases and functional status), and subjective food insecurity and hunger questions. In addition, the survey also collects substantial health information not normally found in surveys, including data from a physical exam conducted by a doctor, blood and urine tests, and a dietary intake model. Many of the tests are not available for children less than two years of age, so our analysis is restricted to individuals two and older.

Our goal in this paper is to compare the extent to which the food insecurity measures and the standard poverty measure are correlated with nutritional outcomes. In this section, we discuss the 
construction of the various food insecurity and outcome measures that we examine. We summarize these measures in Table 1 and provide details of their construction in the Appendix.

\section{Food Insecurity and Poverty Measures}

As discussed above, the USDA has developed an extensive battery of questions that are included in the CPS to examine food insecurity in the United States. Based on responses to these underlying questions, households are placed into one of the following four groups, in order of increasing food insecurity: ${ }^{6}$

A. Food secure: Households show no or minimal evidence of food insecurity.

B. Food insecure without hunger: Food insecurity is evident in household members' concerns about adequacy of the household food supply and in adjustments to household food management, including reduced quality of food and increased unusual coping patterns. Little or no reduction in members' food intake is reported.

C. Food insecure with hunger (moderate): Food intake for adults in the household has been reduced to an extent that implies that adults have repeatedly experienced the physical sensation of hunger. In most (but not all) food-insecure households with children, such reductions are not observed at this stage for children.

D. Foods insecure with hunger (severe): At this level, all households with children have reduced the children's food intake to an extent indicating that the children have experienced hunger. For some other households with children, this already has occurred at an earlier stage of severity. Adults in households with and without children have repeatedly experienced more extensive reductions in food intake.

These categories have an ordinal quality, with a clear ranking between high and low, and there is an explicit definition of what is likely to be observed at the various levels. For example, only the last category tends to be associated with children experiencing inadequate consumption.

Although the complete CPS food security module is not included in NHANES III, a few very similar questions are included. These questions are asked of the family respondent about all family members and of individuals regarding themselves. Such individual-level questions are not asked in the CPS. Table A1 provides the text of the NHANES questions and the comparable CPS questions.

\footnotetext{
${ }^{6}$ These descriptions come from a USDA report, “Guide to Measuring Household Food Security” (Bickel et al., 2000).
} 
We construct four different measures of food insecurity based on these questions. These measures are summarized in Table 1. The first three measures (FSfam1 through FSfam3) are based on the answers of the family respondent to questions regarding the entire family, and the last measure (FSself) is based on individuals' responses about themselves. FSfam2 and FSfam3 were only asked in the second phase of the survey, thus they are only available for half of the sample. Children under age 12 were generally not asked the self-reported questions, so we exclude children from our analysis of these questions. In the Appendix, we present tabulations from the CPS that suggest that the measure FSfam1 corresponds to a concept that lies somewhere between categories B (food insecure without hunger) and C (food insecure with moderate hunger). The measure FSfam2 corresponds closely to category C and FSfam3 corresponds closely to category D (food insecure with severe hunger). This analysis is very similar to the ranking of questions provided in Hamilton et al. (1997).

As discussed above, we also examine the extent to which poverty is correlated with low consumption. There is much dissatisfaction with the U.S. poverty measure, and many suggestions have been made to improve it so it can better identify low-resource households. ${ }^{7}$ Despite these drawbacks, the poverty measure provides a useful benchmark for the effect of low resources which can be compared to the food insecurity questions.

\section{$\underline{\text { Nutritional Outcomes }}$}

NHANES III collects detailed dietary recall information for the previous day (midnight to midnight) and the 30 days prior to the interview. We use a summary measure of the 24-hour dietary recall information, since the 24-hour recall data correspond most closely to what has previously been analyzed in validation studies. The USDA's Healthy Eating Index (HEI) provides a convenient way to summarize all the dietary recall data available in NHANES III in order to assess overall diet quality (Kennedy et al., 1995). The index is the constructed as the sum of ten underlying components, and each component is

\footnotetext{
${ }^{7}$ See Citro and Michael (1995).
} 
scored between 0 and 10; thus, the highest score possible is 100 . The main drawback of the HEI is that it does not penalize a diet that is high in empty carbohydrates from sweets.

We also use two measures of nutritional status based on the body mass index (BMI) measured during the medical assessment. BMI is defined as (weight in grams)/(height in meters) ${ }^{2}$. We determine whether individuals have low BMI or are overweight/obese. The cutoffs for low BMI and overweight/obesity differ by age and gender as shown in the Appendix. While the discussion of food insecurity often focuses on insufficient consumption, obesity is an important and growing public health problem that disproportionately affects the poor.

While it seems paradoxical that obesity should be a condition that is most prevalent among the poor, the result is well established. The reasons are less clearly understood. Cutler, Glaeser, and Shapiro (2003) show that the increases in obesity have come about as Americans increased their caloric intake and reduced their exercise levels. Technological changes have accelerated both trends, as high calorie foods such as French fries have become inexpensive and readily available, while lifestyles have become more sedentary. Changes in relative prices may make the poor particularly vulnerable to these trends, as, for example, prices of high-calorie junk foods decrease faster than prices of fresh fruits and vegetables; prices of televisions decrease faster than prices of other forms of entertainment that require more effort (such as concert going); and the price of exercise (in the form of health club memberships or transportation to open, crime-free spaces) increases. The poor may also be more likely to lack the education necessary to make wise choices among the myriad foods available.

It is interesting to note that this last generalization about education is likely to be less true among the ranks of the poor elderly, which may include, for example, elderly widows without adequate pension coverage. Also, to the extent that many of the diseases associated with obesity result in shortened lifespans, we may be less likely to observe an association between obesity, poverty, and food insecurity among the elderly. 
In an earlier version of this paper, we also examined total calories, which were computed using a model based on recipe information. However, in view of the fact that the poor may suffer from either too many calories, or too few calories, we found it difficult to interpret results using this measure.

The last measure we examine is a composite based on micronutrients (serum vitamins and minerals) in the blood. The relationship between micronutrient intakes and blood levels of these nutrients is complicated. Because the body can store some vitamins and minerals for long periods, it is not anomalous to find a respondent who has not recently consumed the recommended amount of some vitamin and yet is not deficient in that vitamin according to blood tests. Moreover, there are genetic components to certain deficiencies, and serum levels of nutrients are influenced by other behaviors such as drinking and smoking, and by conditions such as pregnancy. Nevertheless, blood tests can provide solid, objective evidence of poor diets when properly interpreted.

In an earlier version of this paper, we examined serum values of vitamins $\mathrm{A}, \mathrm{C}$, and folate separately. We also looked at whether someone was anemic based on hemoglobin and hematocrit levels. All low serum values for vitamins or minerals are cause for concern, but anemia may be particularly pernicious since even slight deficiencies in iron are associated with impaired cognitive functioning, especially in children. The composite measure we examine in this paper is coded as one if the person has a low serum value of vitamins $\mathrm{A}, \mathrm{C}$, or folate, or is anemic. Table A4 presents the cutoff values we use to determine low serum levels of vitamins and minerals. These values are taken from a standard internal medicine textbook (Wilson et al., 1991).

\section{$\underline{\text { Sample Characteristics }}$}

In Table 2, we present sample sizes and sample means for the various measures. Because some of the measures of interest were not asked in all versions of the survey, we use all the data available for any 
particular analysis. $^{8}$ For all of our analyses, we use the sample weights for the MEC and home-examined sample, that is for the sample of all those who had the medical examination.

For each age group, Table 2 gives means separately for four groups defined by whether or not the person was poor, and by whether or not the person was food insecure (according to the FSfam1). Unsurprisingly, most people who are not poor are not food insecure. What is more surprising, is that only a minority of poor households report food insecurity, and that a non-trivial fraction of those reporting food insecurity are not poor. This latter generalization is particularly true among the elderly, where 51 poor persons and 34 non-poor persons report food insecurity. Thus, Table 2 demonstrates that poverty and food insecurity are distinct concepts which might be expected to have different effects on nutritional outcomes.

Examining the means by age indicates that food insecurity is most prevalent in families with children. However, even in these families, a minority (approximately one quarter) of households with any food insecurity report that children are skipping meals (FSfam3). The levels and patterns of reported food insecurity appear to be reasonable except for one anomaly — namely, the frequency of positive responses to FSfam1 (sometimes or often not enough food for the family) is low relative to the responses for the other questions. However, our estimates of the number of households that report yes to FSfam2 and FSfam3 are similar to those found by researchers using the CPS. We obtain 6.0 and 2.6 percent, respectively, while Andrews, Nord, Bickel, and Carlson (2000) report the analogous proportions in the CPS to be 6.5 and 2.0 percent.

Table 2 also presents the means of the nutritional outcome measures for each age group. The Healthy Eating Index shows remarkably little variation across the four poverty/food insecurity groups, suggesting that even those who are not poor and not food insecure tend to have low quality diets.

${ }^{8}$ Specifically, four versions of the NHANES III questionnaire were used over the 6 years that the survey was fielded. Two of the food security questions (FSfam2 and FSfam3) were asked in only two versions of the survey. In addition, certain lab results were not reported for individuals of varying ages; this particularly affects the sample sizes for children 2 to 5 years old. 
However, obesity does tend to increase both with poverty and with food insecurity, and is a significant problem among adults in this sample. Conversely, the fraction of people with low BMI is lower in the poor/food insecure group among children, but higher in this group among adults. Finally, the poor/food insecure group tends to be more likely to have low serum values of nutrients than those in the not poor/not food insecure group. But it is striking that among children, the highest rates of low serum nutrients are recorded for those who are not poor but nevertheless report food insecurity.

The last three rows of each panel of Table 2 show breakdowns by race and Hispanic ethnicity. Unsurprisingly, blacks and Hispanics are over-represented in the poor/food insecure group.

\section{METHODS}

We estimate models of the following form:

$$
\text { Outcome }_{i}=\alpha+\text { Measure }_{i} \beta+X_{i} \gamma+\varepsilon_{i} \text {, }
$$

where Outcome $_{i}$ is a consumption or nutritional outcome measure, Measure ${ }_{i}$ is a vector of poverty or food insecurity measures, and $X_{i}$ are other characteristics that describe the composition of the sample. The coefficients $\beta$ measure the differences in outcomes associated with poverty and food insecurity.

We estimate the regressions separately for the $2-5,6-11,12-17,18-64$, and $65+$ age groups. For each subgroup, we first estimate the model including only poverty, then include both poverty and FSfam1 (which is the food insecurity measure available for the largest sample in our data), and finally include all of the available food insecurity measures. This procedure allows us to gauge the extent to which controlling for food insecurity as well as poverty increases the explanatory power of our models.

We include age, gender, and race in the $X$ vector to control for potential compositional differences related to physiologic processes. We also include urban residence and census region to 
control for potential compositional differences related to regional food prices and diets. ${ }^{9}$ All of the regressions are weighted using the NHANES III MEC sample weights as described above. Note that while we present linear probability models for ease of interpretation, estimation using logit models produced very similar results for dichotomous dependent variables. To compute the coefficients and standard errors, we explicitly account for the complex survey design of the NHANES by using a procedure that specifies the weights, strata, and the primary sampling units. ${ }^{10}$

\section{RESULTS}

Regression estimates are presented in Tables 3 through 8. Each panel/column combination represents a separate regression. For example, Table 3 presents the results for 16 different regressions. We withhold the other coefficient estimates for the sake of brevity.

Table 3 displays results for the $2-5$ age group. The table indicates that children in poverty have less healthy diets (by 1 to 2 points on the HEI), are 3 percentage points more likely to be overweight, are correspondingly 2 percentage points less likely to have low BMI, and are 7 percent more likely to have low serum values of nutrients. Thus, poverty status is predictive of nutritional outcomes. The first panel shows that adding the FSfam1 measure to the model has little effect on the estimated effect of poverty and does not improve the "fit" of the model as measured by the R-squared. In addition, FSfam1 does not have a statistically significant effect in any of the models.

Panel 2 indicates that adding a richer set of food insecurity measures does not change these basic findings, though it does tend to increase the estimated effects of poverty. It is remarkable that the variable FSfam3, which asks explicitly about children skipping meals, has no predictive power once poverty is

\footnotetext{
${ }^{9}$ Specifically, we include age indicators, a gender indicator, race indicators (Hispanic, black, and other), and a complete set of interactions between an urban indicator and census region indicators (Northeast, Midwest, West, and South) in most regressions.

${ }^{10}$ We use the survey command options in STATA 7 to perform our analysis, and we use the total PSU and strata variables (pooled across both survey phases) and the sample weights for the MEC and home-examined sample from the NHANES.
} 
included in the model. In an earlier version of the paper, when FSfam3 was entered as the only element of the vector Measure ${ }_{i}$, it was associated with lower HEI (by 3 points) and a higher incidence of low BMI, but it was not significantly correlated with low serum values for nutrients.

Table 4 indicates that neither poverty nor food insecurity are good predictors of nutritional outcomes among children 6 to 11 . When all of the food insecurity measures are entered in the second panel, FSfam1 is estimated to reduce the incidence of overweight. But given that FSfam1 has no effect in the full sample in Panel 1, the Panel 2 result is likely to be an artifact of collinearity between the various FSfam measures (note that FSfam2 and FSfam3 are estimated to have positive effects on the incidence of overweight).

Table 5 suggests that food insecurity is associated with 3 point reduction in the HEI among 12-17 year olds, while poverty has little effect. However, the Panel 2 estimates in which we include the different measures of food insecurity also appear to suffer from collinearity making it difficult to assess whether nutritional outcomes worsen with more severe food insecurity. Neither poverty nor food insecurity have any significant effect on other outcome variables in this age group.

Table 6 shows that adults aged 18-64 are the group for whom the food insecurity measure appears to be most predictive. In this group, poverty predicts lower HEI, a higher incidence of obesity, and a higher probability of being low in serum nutrients. However, FSfam1 has an independent effect on the HEI and on the probability of being low in serum nutrients. And panel 2 shows that it is FSfam3, the most severe measure of food insecurity that has the largest negative effect on the Healthy Eating Index.

Table 7 shows estimates for the elderly. The models for the HEI score and "LowSum" are qualitatively similar to those for adults less than 65, although the effects of food insecurity are somewhat weaker. The biggest difference between the elderly and adults less than 65 is that neither poverty nor food insecurity predict obesity in this group, while food insecurity increases the probability of low BMI. Panel 2 shows that the self-reported measure has the strongest effect on the probability of low BMI, and is also negatively correlated with the probability of obesity. 
Table 8 presents separate analyses by race and ethnicity. In order to economize on space, we present only models with both poverty and FSfam1, the broadest food insecurity measure. While the overall pattern of results is qualitatively similar to that discussed above, these estimates suggest that there are some interesting differences across race and ethnic groups. For example, the negative effect of poverty on the HEI among 2-5 year olds is concentrated among blacks and Hispanics. Poverty appears to increase the incidence of overweight in this age group only among Hispanics, and poverty increases the probability of being low in serum nutrients only among blacks.

Among children 6-11, we find a significant effect of poverty on the probability of being low in serum nutrients among Hispanics. We also find a marginally significant negative effect of food insecurity on the HEI among whites. Among 12-17 year olds, self-reports of food insecurity are associated with a higher incidence of obesity among Hispanics, but we find no other statistically significant effects.

The rest of the table shows results for adults 18-64 and for the elderly. Among adults, poverty has a negative effect on the HEI and increases the probability of being low in serum nutrients among both whites and blacks, and also has a positive effect on obesity among whites. Household food insecurity (FSfam1) reduces the HEI among whites and also has large effects on the probability of being low in serum nutrients among both whites and blacks. Self-reported food insecurity (FSself) is associated with increased obesity among both whites and Hispanics, as well as an increased probability of being low in serum nutrients among Hispanics. Among the elderly, poverty reduces the HEI by a similar amount in all three groups (though the point estimates for Hispanics are not statistically significant). Poverty is also associated with a higher probability of having low serum nutrients among elderly Hispanics.

Food insecurity is also predictive of lower HEI scores among elderly Hispanics and whites. In fact, the coefficients of -8.21 and -5.73 on FSfam1 for Hispanics and whites, respectively, are the largest estimated effects of food insecurity in this study. Food insecurity (FSfam1) also increases the probability of low serum nutrients among elderly Hispanics—-the estimated effect (.19) is large and of the same magnitude to the estimated effect of poverty. 


\section{DISCUSSION AND CONCLUSIONS}

Significant resources have been devoted to developing measures of food insecurity and hunger in the United States. This study adds to the growing literature that seeks to investigate the meaning of these measures by comparing the estimated effects of food insecurity indicators to those of the traditional measure of material hardship, poverty.

Our results lead to several conclusions. First, poverty is predictive of poorer nutritional outcomes among preschoolers and adults, though not among school aged children. Poor people tend to have lower scores on the Healthy Eating Index, and are more likely to have low serum nutrient levels. This finding confirms that the traditional poverty measure, whatever its limitations, is still predictive of material hardship in this country. We also find that non-elderly poor individuals are more likely to be obese, which is again consistent with previous research and suggests that poor Americans eat too much of the wrong sort of calories, rather than getting insufficient calories overall.

Second, among school-age children (6 to 17), we find few systematic differences in diet either between the poor and the non-poor or between the food secure and the food insecure. There are several potential explanations for this pattern. First, it is possible that the nutritional outcomes of school-age children are not as closely tied to family resources as are the outcomes of younger children and adults. For example, these children might have the ability to supplement their consumption opportunities at school, during extracurricular activities, at friends' and neighbors' homes, or through working. Thus, it is possible that our null results reflect the success of the food safety net available to school age children. Another possibility is that the physiologic processes that translate consumption into outcomes are much noisier for this group, making any differences more difficult to detect.

Third, we find that the food insecurity measures have little predictive power in models of children's nutritional outcomes, once poverty has been controlled for. It is remarkable that even the most severe measure of food insecurity, FSfam3, which refers specifically to children missing meals, has little predictive power among children. 
Fourth, we find that food insecurity is a significant predictor of nutritional outcomes among adults. Among non-elderly adults, food insecure individuals have a less healthy diet and are more likely to be low in serum nutrients. The self-reported measure of food insecurity is also positively related to obesity. Poor, food insecure elderly have less healthy diets, and are more likely to have low BMI then other elderly. This finding suggests that while non-elderly adults have access to sufficient calories (which may nevertheless be of low quality in terms of nutrient value), food insecure elderly lack access to calories. This lack of access may reflect problems shopping for and preparing food in addition rather than only problems due to lack of income.

Fifth, there are important differences in these patterns by race and ethnicity. Among children, poverty appears to have more negative effects on the quality of the diet and on serum nutrient levels among blacks and Hispanics than among whites. In contrast, among adults 18 to 64, the effects of poverty are most pronounced for whites and blacks, while food insecurity is associated with poorer outcomes in all three groups. Finally, we find large impacts of poverty among elderly Hispanics, as well as large effects of food insecurity on elderly Hispanics and whites.

Our findings suggest several underlying behavioral issues of interest. For example, poverty is associated with low BMI among the elderly, but has the opposite relationship among the young. These findings could be explained by models that consider quality/quantity and time/money trade-offs in food production. Second, the fact that poverty appears to have a more negative effect on the nutritional status of minority children is worth further study. As a third example, we find much variation by age in the relationship between poverty and outcomes. Adult outcomes are more correlated with food insecurity than child outcomes, and outcomes of young children are more correlated with poverty than are the outcomes of older children. It is possible that parents allocate household resources in a way that protects young children from the effects of poverty, and that older children in food insecure households have more opportunities to supplement their consumption outside the home. It would be tremendously useful to have a better understanding of these protective family behaviors. 


\section{APPENDIX}

Food insecurity questions. We list the six food insecurity questions asked in NHANES III in Table A1. Questions HFF7 and HFF8 were only asked in two of four survey versions. We only used actual self-responses to questions DRPQ7 and DRPQ8 for individuals age 12 and older, excluding proxy or joint proxy/self-responses.

In order to examine the relationship between the questions in the NHANES and the food security composite categories, we directly compare the similar CPS questions (see Table A1) to the CPS composite categories using April 1999 CPS data. The composite categories were discussed in Section 3. We examine the relationship by comparing cross-tabulations, computing the amount of agreement between the measures, and noting whether the disagreement is systematic. We present the results of these comparisons in Table A2.

The first food insecurity question (sometimes or often do not have enough to eat) is most closely related to category C, as measured by the amount of agreement between the measures (94.2 percent). Where there is disagreement between the measures, it is most often the result of individuals who are not labeled as "food insecure with moderate hunger" nevertheless answering that they "sometimes or often do not have enough to eat”. If we compare answers to the first food insecurity question with category B, the results suggest that people who were "food insecure without hunger" sometimes did not answer that they "sometimes or often did not have enough to eat". Thus, it appears that the first NHANES food insecurity question measures a concept somewhere between the USDA’s category B and category C.

The last two questions correspond much more closely to particular categories. The question regarding whether adults skip meals agrees most often with category C (97.8 percent), with the disagreement not being very systematic. The question regarding children skipping meals agrees most frequently with category D (99.5 percent), again with the disagreement not being very systematic. 
Poverty measure. The income-to-poverty ratio is based on the official U.S. poverty definition and is computed by NHANES III. The underlying income information comes from one total income question, but the respondents are first prompted about the existence of many different sources of income (e.g., labor income and transfer income).

Nutritional Outcomes. The underlying ten components are listed in Table A3; the HEI is computed by NHANES III from 24-hour dietary recall data. The cutoff values for "low” serum nutrient levels are shown in Table A4. Although blood was potentially taken from individuals of all ages, vitamin A, C levels were not reported for children under 4 and vitamin C levels were not reported for 4and 5-year-olds. 
TABLE A1

Comparing Food Insecurity Questions in the NHANES and CPS

\section{NHANES Questions \\ CPS Questions}

\section{Household Level Questions}

HFF4. Do you have enough food to eat, sometimes not enough to eat, or often not enough to eat?

SS1A. Which of the following statements best describes the amount of food eaten in your household-enough to eat, sometimes not enough to eat, or often not enough to eat?

HFF5. Thinking about the past month, how many days did (you/your family) have no food or money to buy food?

HFF7. Thinking about the past month, did (you/adult members of your family) ever cut the size of your meals because there was not enough money or food? [yes/no]

HFF8. Thinking about the past month, did you cut the size of your children's meals or did they skip meals because there was not enough money for food? [yes/no]
SHM2. Now think about the last 30 days. Did (you/adults in your household) ever cut the size of your meals or skip meals in the last 30 days because there wasn't enough food?

SSHM2/SSHM4. In the last 12 months, since October of last year, did you ever cut the size of (any of the children)'" meals because there wasn't enough money for food? Did this ever happen in the last 30 days?

HRSF12M2. The composite food security scale computed by the CPS.

\section{Individual-Level Questions}

DRPQ7. During the past month did (you/_) skip any [no individual level questions available] meals because there wasn't enough food or money to buy food? [yes/no]

DRPQ8. How many days in the past month did (you/_) skip any meals because there wasn’t enough food or money to buy food?

Note: CPS Question SS1A was asked of 4 of 8 of the April rotation groups. Questions SSHM2 and SSHM4 were asked of 7 of 8 rotation groups. 
TABLE A2

Relationships Between Single Food Insecurity Questions, and the Food Insecurity Scale

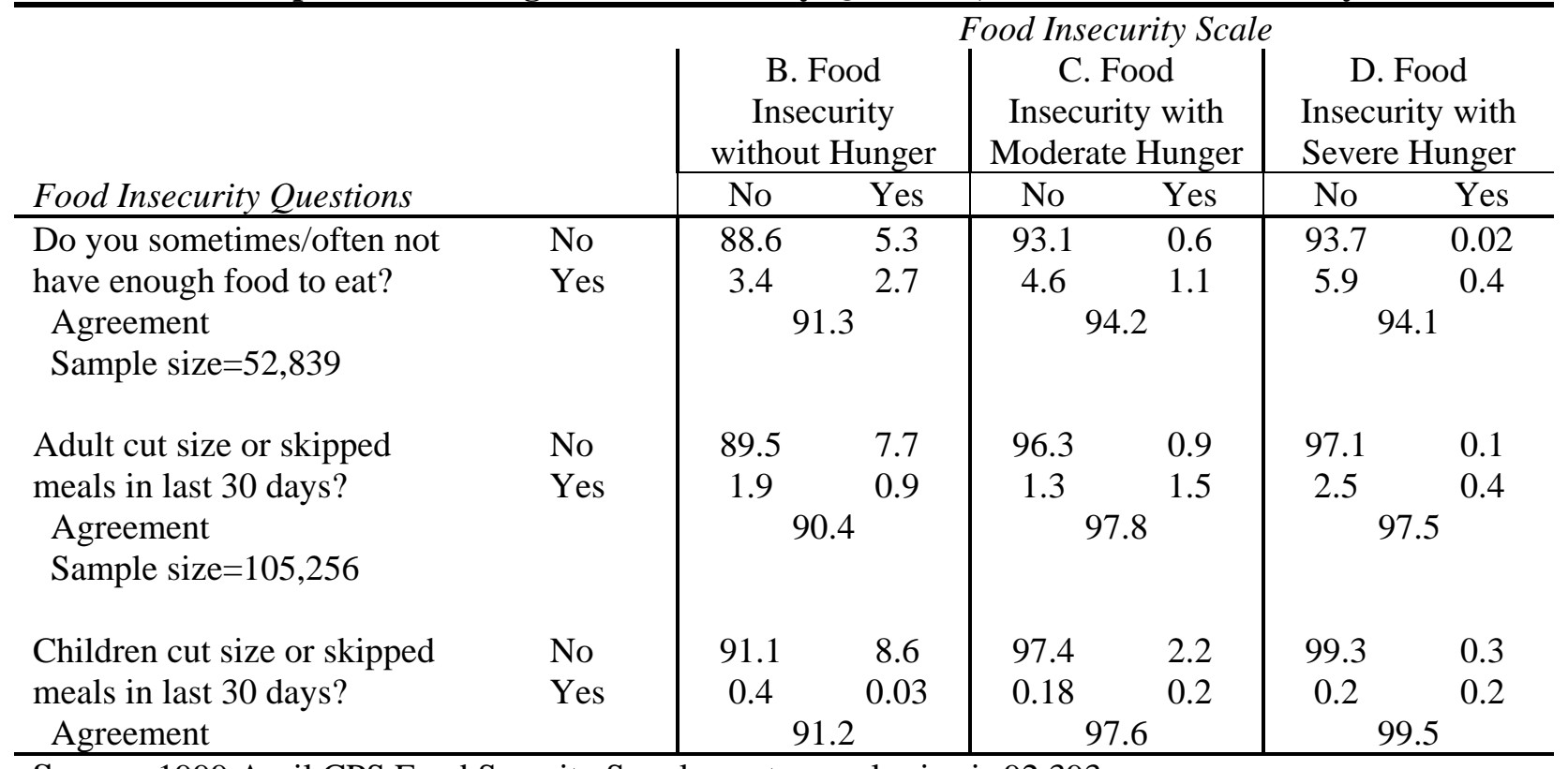

Source: 1999 April CPS Food Security Supplement; sample size is 92,393.

Notes: These tabulations are weighted. For each question, we only include the CPS households that were asked the specific question, dropping the households that were instead asked the similar experimental questions. 
TABLE A3

Components of the HEI

\begin{tabular}{lll}
\hline \multicolumn{1}{c}{ Component } & \multicolumn{1}{c}{ Criteria for Score of 0} & \multicolumn{1}{c}{ Criteria for Score of 10 } \\
\hline 1. Grains & 0 servings & $6-11$ servings* \\
2. Vegetables & 0 servings & $3-5$ servings \\
3. Fruits & 0 servings & $2-4$ servings \\
4. Milk & 0 servings & $2-3$ servings \\
5. Meat & 0 servings & $2-3$ servings \\
6. Total fat & $>44 \%$ calories from fat & $<31 \%$ calories from fat \\
7. Saturated fat & $>14 \%$ calories from s.f. & $<10 \%$ calories from s.f. \\
8. Cholesterol & $>449 \mathrm{mg}$ & $<300 \mathrm{mg}$ \\
9. Sodium & $>4,799 \mathrm{mg}$ & $<2,400 \mathrm{mg}$ \\
10. Variety & $<4$ different categories a day & $>7$ different categories a day \\
\hline
\end{tabular}

Note: This table is taken from the NHANES III manual. People with consumption or intakes between the maximum and minimum ranges or amounts were assigned scores proportionately. 
TABLE A4

Laboratory Measures of Inadequate Serum Nutrients

\begin{tabular}{lll}
\hline \multicolumn{1}{c}{ Lab. Measure } & \multicolumn{1}{c}{ Ages/Gender } & \multicolumn{1}{c}{ Criteria for Inadequacy } \\
\hline Anemia & $2-11$ & hemoglobin $<11.5 \mathrm{~g} / \mathrm{dL}$ and hematocrit $<35 \%$ \\
& $12-17$ & hemoglobin $<12 \mathrm{~g} / \mathrm{dL}$ and hematocrit $<37 \%$ \\
& $>17 /$ Female & hemoglobin $<12 \mathrm{~g} / \mathrm{dL}$ and hematocrit $<36 \%$ \\
& $>17 /$ Male & hemoglobin $<13 \mathrm{~g} / \mathrm{dL}$ and hematocrit $<39 \%$ \\
Low BMI & $2-20$ & $\mathrm{BMI}<5 \%$ tile $($ gender/age specific) \\
& $21-$ & $\mathrm{BMI}=<18.5$ \\
Obesity/Overweight & $2-20$ & $\mathrm{BMI}>=95 \%$ tile (gender/age specific) \\
& $21-$ & $\mathrm{BMI}>=30$ \\
Low vitamin C & & $<11.4 \mathrm{mmol} / \mathrm{L}$ \\
Low vitamin A & $2-11$ & $<1.05 \mu \mathrm{mol} / \mathrm{L}$ \\
& $>11$ & $<0.7 \mu \mathrm{mol} / \mathrm{L}$ \\
Low folate & & $<7 \mathrm{nmol} / \mathrm{L}$ \\
\hline
\end{tabular}

Note: All values were taken from Wilson et al. (1991), except for low BMI and obesity, which were taken from the CDC. 


\section{References}

Alaimo, K, Craig Olson, and E. Frongillo. 2001. "Food Insufficiency and American School-Aged Children’s Cognitive, Academic, and Psychosocial Development”, Pediatrics, 108:44-51.

Andrews, Margaret, Gary Bickel and Steven Carlson. 1998. "Household Food Security in the United States in 1995: Results from the Food Security Measurement Project” Family Economics and Nutrition Review, v11 \#1\&2, 17-28.

Andrews, Margaret, Mark Nord, Gary Bickel, and Steven Carlson. 2000. Household Food Security in the United States, 1999. Washington, DC: Economic Research Service/USDA.

Bickel, Gary, Mark Nord, Cristofer Price, William Hamilton, and John Cook. 2000. Guide to Measuring Household Food Security, Revised 2000. Alexandria, VA: U.S. Department of Agriculture, Food and Nutrition Service.

Borjas, George. 2002. “Food Insecurity and Public Assistance”, NBER Working Paper \#9236, Cambridge MA: NBER.

Citro, Constance, and Robert Michael, eds. 1995. Measuring Poverty. Washington, DC: National Academy Press.

Currie, Janet and Jayanta Bhattacharya. 2001. "Youths at Nutritional Risk: Malnourished or Misnourished?", in Risky Behavior Among Youths: An Economic Analysis, Jonathon Gruber (ed) (Chicago: University of Chicago Press for NBER).

Cutler, David, Edward Glaeser, and Jesse Shapiro. "Why Have Americans Become More Obese?” Journal of Economic Perspectives, Summer 2003.

Dietz, W.H. and F.L. Trowbridge. 1990. "Symposium on the Identification and Prevalence of Undernutrition in the United States: Introduction”, The Journal of Nutrition, 120(8), 917-918.

Derrickson, Joda, Jennifer Anderson, and Anne Fisher. 2000. "Concurrent Validity of the Face Valid Food Security Measure.” Discussion Paper no. 1206-00, Institute for Research on Poverty, University of Wisconsin-Madison.

Dixon, Lori Beth, Marilyn Winkleby, and Kathy Radimer. 2001 "Dietary Intakes and Serum Nutrients Differ Between Adults from Food-Insufficient and Food-Sufficient Families: Third National Health and Nutrition Examination Survey, 1988-1994, American Society for Nutritional Sciences, 1232-1246.

Hamilton, William, John Cook, William Thompson, Lawrence Buron, Edward Frongillo, Christine Olson, and Cheryl Wehler. 1997. Household Food Security in the United States in 1995: Technical Report of the Food Security Measurement Project. Alexandria, VA: United States Department of Agriculture, Food and Consumer Service, Office of Analysis and Evaluation.

Jencks, Christopher and Susan Mayer. 1989. “Poverty and the Distribution of Material Hardship”, Journal of Human Resources, 24(1), 88-114.

Kennedy, Eileen, James Ohls, Steven Carlson, and Kathryn Fleming. 1995. "The Healthy Eating Index: Design and Applications.” Journal of the American Dietetic Association 95 (10): 1103-1108. 
Kowaleski-Jones, Lori and Rachel Dunifon. 2001. "Moderating the Effects of Food Insecurity on Child Outcomes: The Role of Food Assistance Programs”, Paper presented to the 2001 Annual Meetings of the Population Association of America, Washington D.C., March.

Lenhart, N.M. and M.H. Read. 1989. "Demographic Profile and Nutrient Intake Assessment of Individuals Using Emergency Food Programs”, Journal of the American Dietetic Association, 89(9), 1269-1972, Sept.

Orshansky, Mollie. 1965. "Counting the poor: Another look at the poverty profile. Social Security Bulletin, 28(1), 3-29.

President's Task Force on Food Assistance. 1984. Report of the President's Task Force on Food Assistance (Washington D.C.: U.S. Government Printing Office).

Rose, Donald. 1999. "Economic Determinants and Dietary Consequences of Food Insecurity in the United States”, The Journal of Nutrition, 129, 517S-520S.

Rose, Donald and Victor Oliveria. 1997. "Nutrient Intakes of Individuals from Food-Insufficient Households in the United States”, American Journal of Public Health, 87(12), 1956-61.

Rose, Donald, P. Peter Basiotis and Bruce W. Klein. 1995. "Improving Federal Efforts to Assess Hunger and Food Insecurity”, Food Review, Jan-April, 18-23.

Siefert, Kristine, Colleen Heflin, Mary Corcoran and David Williams. 2001. "Food Insufficiency and the Physical and Mental Health of Current and Former Welfare Recipients", Paper presented at the Association of Public Policy and Management Conference, Washington, D.C.

Slesnick, Daniel. 1993. “Gaining Ground: Poverty in the Postwar United States”, Journal of Political Economy, 101(1), 1-38.

Weinreb, Linda, Cheryl Wehler, Jennifer Perloff, Richard Scott, David Hosmer, Linda Sagor, and Craig Gundersen. 2002. “Hunger: Its Impact on Children’s Health and Mental Health”, Pediatrics, $110: 4,41$.

Wilson, J.D., E. Braunwald, K. J. Isselbacher, R. G. Petersdorf, J. B. Martin, A. S. Fauci, R. K. Root, eds. 1991. Harrison's Principles of Internal Medicine. New York: McGraw-Hill.

Winship, Scott, and Christopher Jencks. 2002. "Changes in Food Security after Welfare Reform: Can We Identify a Policy Effect?”, Joint Chicago/Northwestern Center Poverty Research, Working Paper, March. 
TABLE 1

Description of Key Variables

\begin{tabular}{|c|c|c|}
\hline Variables & Question & Notes \\
\hline \multicolumn{3}{|c|}{ Food Insecurity and Poverty Measures } \\
\hline - FSfam1 & $\begin{array}{l}\text { - Family respondent reports there is } \\
\text { not enough food sometimes or often }\end{array}$ & \\
\hline - FSfam2 & $\begin{array}{l}\text { - Family respondent reports adults } \\
\text { skipped meals }\end{array}$ & - Not available for half of the sample \\
\hline - FSfam3 & $\begin{array}{l}\text { - Family respondent reports children } \\
\text { skipped meals }\end{array}$ & $\begin{array}{l}\text { - Not available for half of the } \\
\text { sample. Only asked if child under } \\
16 \text { is present. }\end{array}$ \\
\hline $\begin{array}{l}\text { - FSself } \\
\text { - Poverty }\end{array}$ & $\begin{array}{l}\text { - Self-report of skipping any meals } \\
\text { - Poverty indicator based on U.S. } \\
\text { poverty definition }\end{array}$ & $\begin{array}{l}\text { - Disregarded for children under } 12 \\
\text { - Income is collected with one } \\
\text { question }\end{array}$ \\
\hline \multicolumn{3}{|c|}{ Outcome Measures } \\
\hline $\begin{array}{l}\text { - HEI } \\
\text { - Low BMI }\end{array}$ & $\begin{array}{l}\text { - Healthy Eating Index (HEI) } \\
\text { - Based on age/gender cut-offs for } \\
\text { BMI }\end{array}$ & - See appendix for details \\
\hline $\begin{array}{l}\text { - Obesity/ } \\
\text { Overweight }\end{array}$ & $\begin{array}{l}\text { - Based on age/gender cut-offs for } \\
\text { BMI }\end{array}$ & $\begin{array}{l}\text { - Children under } 12 \text { are } \\
\text { appropriately referred to as } \\
\text { overweight, not obese }\end{array}$ \\
\hline - LowSum & $\begin{array}{l}\text { - Summary measure equal to } 1 \text { if the } \\
\text { person is low vitamins A, C, or } \\
\text { Folate or Anemic (as available) }\end{array}$ & - See notes below \\
\hline - LowA & - Low vitamin A & - Not available for children under 4 \\
\hline - LowC & - Low vitamin C & - Not available for children under 5 \\
\hline - Anemic & $\begin{array}{l}\text { - Low folate } \\
\text { - Anemic, based on hemoglobin and } \\
\text { hematocrit levels }\end{array}$ & - Not available for children under 4 \\
\hline
\end{tabular}


TABLE 2

Sample Means by Age Group, Poverty and Food Insecurity Status

\begin{tabular}{|c|c|c|c|c|c|c|c|c|}
\hline Variables & $\begin{array}{c}\text { Not Poor } \\
\text { Not FI }\end{array}$ & $\begin{array}{c}\text { Not Poor } \\
\text { FI }\end{array}$ & $\begin{array}{l}\text { Poor } \\
\text { Not FI }\end{array}$ & $\begin{array}{c}\text { Poor } \\
\text { FI }\end{array}$ & $\begin{array}{c}\text { Not Poor } \\
\text { Not FI }\end{array}$ & $\begin{array}{l}\text { Not Poor } \\
\text { FI }\end{array}$ & $\begin{array}{c}\text { Poor } \\
\text { Not FI }\end{array}$ & $\begin{array}{c}\text { Poor } \\
\text { FI }\end{array}$ \\
\hline & \multicolumn{4}{|c|}{$2-5$ year olds $(N=4,248)$} & \multicolumn{4}{|c|}{$6-11$ year olds $(N=3,103)$} \\
\hline $\mathrm{N}$ & 2,407 & 71 & 1,374 & 396 & 1,791 & 68 & 981 & 263 \\
\hline Pop. share & 0.713 & 0.011 & 0.223 & 0.053 & 0.737 & 0.015 & 0.209 & 0.039 \\
\hline FSfam2* & 0.036 & 0.526 & 0.120 & 0.735 & 0.021 & 0.730 & 0.059 & 0.750 \\
\hline FSfam3* & 0.009 & 0.066 & 0.051 & 0.256 & 0.005 & 0.227 & 0.015 & 0.271 \\
\hline FSself & -- & -- & -- & -- & -- & -- & -- & -- \\
\hline HEI & 70.6 & 70.5 & 68.2 & 70.6 & 64.9 & 62.6 & 65.5 & 65.6 \\
\hline Obesity & 0.053 & 0.075 & 0.103 & 0.088 & 0.139 & 0.136 & 0.149 & 0.141 \\
\hline Low BMI & 0.072 & 0.046 & 0.056 & 0.055 & 0.045 & 0.030 & 0.028 & 0.032 \\
\hline LowSum & 0.202 & 0.338 & 0.298 & 0.249 & 0.143 & 0.098 & 0.192 & 0.164 \\
\hline White & 0.750 & 0.458 & 0.369 & 0.316 & 0.760 & 0.544 & 0.440 & 0.312 \\
\hline Black & 0.107 & 0.173 & 0.294 & 0.261 & 0.112 & 0.288 & 0.267 & 0.245 \\
\hline \multirow[t]{2}{*}{ Hispanic } & 0.104 & 0.368 & 0.273 & 0.331 & 0.096 & 0.168 & 0.221 & 0.360 \\
\hline & \multicolumn{4}{|c|}{$12-17$ year olds $(N=2,151)$} & \multicolumn{4}{|c|}{$18-64$ year olds $(N=11,853)$} \\
\hline $\mathrm{N}$ & 1,324 & 48 & 602 & 177 & 8,745 & 258 & 2,287 & 563 \\
\hline Pop. share & 0.771 & 0.014 & 0.172 & 0.043 & 0.863 & 0.012 & 0.102 & 0.023 \\
\hline FSfam2* & 0.045 & 0.630 & 0.099 & 0.853 & 0.029 & 0.810 & 0.078 & 0.725 \\
\hline FSfam3* & 0.008 & 0.367 & 0.013 & 0.276 & 0.009 & 0.261 & 0.038 & 0.252 \\
\hline FSself & 0.029 & 0.129 & 0.082 & 0.040 & 0.015 & 0.222 & 0.053 & 0.316 \\
\hline HEI & 60.4 & 54.0 & 59.2 & 58.4 & 63.2 & 56.9 & 59.5 & 58.7 \\
\hline Obesity & 0.108 & 0.030 & 0.155 & 0.181 & 0.213 & 0.193 & 0.249 & 0.283 \\
\hline Low BMI & 0.021 & 0.029 & 0.024 & 0.014 & 0.026 & 0.056 & 0.032 & 0.034 \\
\hline LowSum & 0.192 & 0.317 & 0.219 & 0.212 & 0.295 & 0.481 & 0.417 & 0.504 \\
\hline White & 0.764 & 0.556 & 0.388 & 0.473 & 0.800 & 0.575 & 0.476 & 0.472 \\
\hline Black & 0.106 & 0.334 & 0.296 & 0.203 & 0.091 & 0.241 & 0.263 & 0.203 \\
\hline Hispanic & 0.083 & 0.110 & 0.280 & 0.298 & 0.077 & 0.184 & 0.224 & 0.290 \\
\hline \multicolumn{5}{|c|}{$65+$ year olds $(N=3,330)$} & & & & \\
\hline $\mathrm{N}$ & 2,676 & 34 & 569 & 51 & & & & \\
\hline Pop. share & 0.884 & 0.009 & 0.101 & 0.005 & & & & \\
\hline FSfam2* & 0.014 & 0.615 & 0.031 & 0.890 & & & & \\
\hline FSfam3* & -- & -- & -- & -- & & & & \\
\hline FSself & 0.005 & 0.082 & 0.025 & 0.092 & & & & \\
\hline HEI & 69.5 & 60.7 & 64.3 & 63.1 & & & & \\
\hline Obesity & 0.226 & 0.263 & 0.225 & 0.277 & & & & \\
\hline Low BMI & 0.019 & 0.176 & 0.050 & 0.033 & & & & \\
\hline LowSum & 0.180 & 0.417 & 0.318 & 0.398 & & & & \\
\hline White & 0.901 & 0.891 & 0.662 & 0.466 & & & & \\
\hline Black & 0.056 & 0.061 & 0.247 & 0.304 & & & & \\
\hline Hispanic & 0.034 & 0.048 & 0.079 & 0.230 & & & & \\
\hline
\end{tabular}

Notes: All means are weighted; only sample sizes (N) are unweighted. *FSfam2 and FSfam3 have smaller sample sizes; see Table 1. 
TABLE 3

OLS Regression Results for the 2-5 Age Group

\begin{tabular}{|c|c|c|c|c|c|c|c|c|}
\hline \multirow[b]{2}{*}{ Poverty } & \multicolumn{2}{|c|}{ HEI Score } & \multicolumn{2}{|c|}{ Overweight } & \multicolumn{2}{|c|}{ Low BMI } & \multicolumn{2}{|c|}{ LowSum } \\
\hline & $\begin{array}{l}-1.50 \\
(0.83)+\end{array}$ & $\begin{array}{c}-1.82 \\
(0.89) * \\
1.76 \\
(1.66)\end{array}$ & $\begin{array}{c}0.03 \\
(0.01)^{+}\end{array}$ & $\begin{array}{c}0.03 \\
(0.02) \\
-0.01 \\
(0.03)\end{array}$ & $\begin{array}{l}-0.02 \\
(0.01)^{*}\end{array}$ & $\begin{array}{c}-0.02 \\
(0.01)^{*} \\
0.00 \\
(0.02)\end{array}$ & $\begin{array}{c}0.07 \\
(0.03)^{*}\end{array}$ & $\begin{array}{l}0.07 \\
(0.03)^{*} \\
-0.02 \\
(0.05)\end{array}$ \\
\hline $\begin{array}{l}\text { Observations } \\
\text { R-squared }\end{array}$ & $\begin{array}{r}3865 \\
0.05 \\
\end{array}$ & $\begin{array}{r}3865 \\
0.06 \\
\end{array}$ & $\begin{array}{r}4248 \\
0.04 \\
\end{array}$ & $\begin{array}{r}4248 \\
0.04 \\
\end{array}$ & $\begin{array}{r}4248 \\
0.02 \\
\end{array}$ & $\begin{array}{r}4248 \\
0.02 \\
\end{array}$ & $\begin{array}{r}3378 \\
0.05 \\
\end{array}$ & $\begin{array}{r}3378 \\
0.05 \\
\end{array}$ \\
\hline Poverty & $\begin{array}{l}-1.98 \\
(1.13)+\end{array}$ & $\begin{array}{l}-2.77 \\
(1.23)^{*}\end{array}$ & $\begin{array}{c}0.04 \\
(0.02)+\end{array}$ & $\begin{array}{c}0.05 \\
(0.03)\end{array}$ & $\begin{array}{l}-0.02 \\
(0.01)\end{array}$ & $\begin{array}{l}-0.02 \\
(0.01)\end{array}$ & $\begin{array}{l}0.11 \\
(0.03) * *\end{array}$ & $\begin{array}{c}0.11 \\
(0.04) *\end{array}$ \\
\hline FSfam1 & & $\begin{array}{c}3.52 \\
(2.51)\end{array}$ & & $\begin{array}{l}-0.01 \\
(0.03)\end{array}$ & & $\begin{array}{l}-0.03 \\
(0.03)\end{array}$ & & $\begin{array}{l}-0.03 \\
(0.08)\end{array}$ \\
\hline FSfam2 & & $\begin{array}{c}1.08 \\
(2.15)\end{array}$ & & $\begin{array}{l}-0.02 \\
(0.03)\end{array}$ & & $\begin{array}{c}0.03 \\
(0.03)\end{array}$ & & $\begin{array}{c}0.05 \\
(0.08)\end{array}$ \\
\hline FSfam3 & & $\begin{array}{l}-3.58 \\
(3.03)\end{array}$ & & $\begin{array}{l}-0.02 \\
(0.04)\end{array}$ & & $\begin{array}{c}0.03 \\
(0.06)\end{array}$ & & $\begin{array}{l}-0.08 \\
(0.08)\end{array}$ \\
\hline Observations & 1861 & 1861 & 2055 & 2055 & 2055 & 2055 & 1825 & 1825 \\
\hline R-squared & 0.06 & 0.07 & 0.08 & 0.08 & 0.02 & 0.02 & 0.07 & 0.07 \\
\hline
\end{tabular}

Notes: Each column in each panel represents the result from a separate regression, where the dependent variable is listed as a column heading. All regressions include age dummies, race dummies, a male dummy, and region*urban dummies. The results take into account the complex survey design, including the weights. Standard errors are in parentheses.

+ denotes significance at the 0.10 level; * denotes significance at the 0.05 level; ** denotes significance at the 0.01 level. 
TABLE 4

OLS Regression Results for the 6-11 Age Group

\begin{tabular}{|c|c|c|c|c|c|c|c|c|}
\hline \multirow[b]{2}{*}{ Poverty } & \multicolumn{2}{|c|}{ HEI Score } & \multicolumn{2}{|c|}{ Overweight } & \multicolumn{2}{|c|}{ Low BMI } & \multicolumn{2}{|c|}{ LowSum } \\
\hline & $\begin{array}{c}0.84 \\
(1.02)\end{array}$ & $\begin{array}{c}0.90 \\
(1.04)\end{array}$ & $\begin{array}{l}-0.01 \\
(0.03)\end{array}$ & $\begin{array}{l}-0.00 \\
(0.03)\end{array}$ & $\begin{array}{l}-0.02 \\
(0.01)\end{array}$ & $\begin{array}{l}-0.02 \\
(0.01)\end{array}$ & $\begin{array}{c}0.03 \\
(0.02)\end{array}$ & $\begin{array}{c}0.04 \\
(0.03)\end{array}$ \\
\hline FSfam1 & & $\begin{array}{l}-0.50 \\
(0.83)\end{array}$ & & $\begin{array}{l}-0.01 \\
(0.03)\end{array}$ & & $\begin{array}{c}0.00 \\
(0.02)\end{array}$ & & $\begin{array}{l}-0.02 \\
(0.04)\end{array}$ \\
\hline Observations & 2957 & 2957 & 3103 & 3103 & 3103 & 3103 & 2767 & 2767 \\
\hline R-squared & 0.05 & 0.05 & 0.02 & 0.02 & 0.01 & 0.01 & 0.04 & 0.04 \\
\hline Poverty & $\begin{array}{c}1.33 \\
(1.55)\end{array}$ & $\begin{array}{c}1.42 \\
(1.66)\end{array}$ & $\begin{array}{l}-0.01 \\
(0.05)\end{array}$ & $\begin{array}{l}-0.00 \\
(0.05)\end{array}$ & $\begin{array}{l}-0.02 \\
(0.02)\end{array}$ & $\begin{array}{l}-0.02 \\
(0.02)\end{array}$ & $\begin{array}{c}0.05 \\
(0.03)+\end{array}$ & $\begin{array}{c}0.05 \\
(0.03)\end{array}$ \\
\hline FSfam1 & & $\begin{array}{c}0.88 \\
(1.49)\end{array}$ & & $\begin{array}{l}-0.13 \\
(0.05)^{*}\end{array}$ & & $\begin{array}{c}0.05 \\
(0.05)\end{array}$ & & $\begin{array}{l}-0.03 \\
(0.05)\end{array}$ \\
\hline FSfam2 & & $\begin{array}{l}-1.84 \\
(1.47)\end{array}$ & & $\begin{array}{c}0.06 \\
(0.06)\end{array}$ & & $\begin{array}{l}-0.06 \\
(0.03)+\end{array}$ & & $\begin{array}{c}0.00 \\
(0.05)\end{array}$ \\
\hline FSfam3 & & $\begin{array}{c}0.58 \\
(1.30)\end{array}$ & & $\begin{array}{c}0.05 \\
(0.07)\end{array}$ & & $\begin{array}{c}0.02 \\
(0.02)\end{array}$ & & $\begin{array}{c}0.10 \\
(0.08)\end{array}$ \\
\hline Observations & 1331 & 1331 & 1390 & 1390 & 1390 & 1390 & 1293 & 1293 \\
\hline R-squared & 0.06 & 0.06 & 0.04 & 0.04 & 0.04 & 0.04 & 0.08 & 0.08 \\
\hline
\end{tabular}

Notes: Each column in each panel represents the result from a separate regression, where the dependent variable is listed as a column heading. All regressions include age dummies, race dummies, a male dummy, and region*urban dummies. The results take into account the complex survey design, including the weights. Standard errors are in parentheses.

+ denotes significance at the 0.10 level; * denotes significance at the 0.05 level; ** denotes significance at the 0.01 level. 
TABLE 5

OLS Regression Results for the 12-17 Age Group

\begin{tabular}{|c|c|c|c|c|c|c|c|c|}
\hline \multirow[b]{2}{*}{ Poverty } & \multicolumn{2}{|c|}{ HEI Score } & \multicolumn{2}{|c|}{ Obesity } & \multicolumn{2}{|c|}{ Low BMI } & \multicolumn{2}{|c|}{ LowSum } \\
\hline & $\begin{array}{l}-0.82 \\
(1.08)\end{array}$ & $\begin{array}{l}-0.16 \\
(0.99)\end{array}$ & $\begin{array}{c}0.04 \\
(0.03)\end{array}$ & $\begin{array}{c}0.04 \\
(0.03)\end{array}$ & $\begin{array}{c}0.00 \\
(0.01)\end{array}$ & $\begin{array}{l}-0.00 \\
(0.01)\end{array}$ & $\begin{array}{c}0.00 \\
(0.01)\end{array}$ & $\begin{array}{l}-0.00 \\
(0.01)\end{array}$ \\
\hline FSfam1 & & $\begin{array}{l}-2.94 \\
(1.42) *\end{array}$ & & $\begin{array}{l}-0.01 \\
(0.04)\end{array}$ & & -0.00 & & -0.00 \\
\hline FSself & & $\begin{array}{l}-2.48 \\
(2.19)\end{array}$ & & $\begin{array}{c}(0.04) \\
0.06 \\
(0.06)\end{array}$ & & $\begin{array}{c}(0.01) \\
0.05 \\
(0.04)\end{array}$ & & $\begin{array}{c}(0.01) \\
0.05 \\
(0.04)\end{array}$ \\
\hline Observations & 2134 & 2134 & 2151 & 2151 & 2151 & 2151 & 2151 & 2151 \\
\hline R-squared & 0.04 & 0.05 & 0.02 & 0.02 & 0.01 & 0.02 & 0.01 & 0.02 \\
\hline Poverty & $\begin{array}{c}0.16 \\
(1.37)\end{array}$ & $\begin{array}{c}0.24 \\
(1.50)\end{array}$ & $\begin{array}{c}0.02 \\
(0.04)\end{array}$ & $\begin{array}{c}0.02 \\
(0.04)\end{array}$ & $\begin{array}{l}-0.01 \\
(0.02)\end{array}$ & $\begin{array}{l}-0.01 \\
(0.02)\end{array}$ & $\begin{array}{c}0.07 \\
(0.04)\end{array}$ & $\begin{array}{c}0.06 \\
(0.04)\end{array}$ \\
\hline FSfam1 & & $\begin{array}{l}-2.48 \\
(1.88)\end{array}$ & & $\begin{array}{l}-0.04 \\
(0.05)\end{array}$ & & $\begin{array}{l}-0.04 \\
(0.04)\end{array}$ & & $\begin{array}{c}0.16 \\
(0.05)^{* *}\end{array}$ \\
\hline FSfam2 & & $\begin{array}{l}4.08 \\
(1.91)^{*}\end{array}$ & & $\begin{array}{c}0.04 \\
(0.06)\end{array}$ & & $\begin{array}{c}0.00 \\
(0.02)\end{array}$ & & $\begin{array}{l}-0.09 \\
(0.03) * *\end{array}$ \\
\hline FSfam3 & & $\begin{array}{l}-4.52 \\
(2.06)^{*}\end{array}$ & & $\begin{array}{l}-0.04 \\
(0.07)\end{array}$ & & $\begin{array}{c}0.14 \\
(0.10)\end{array}$ & & $\begin{array}{c}0.00 \\
(0.09)\end{array}$ \\
\hline FSself & & $\begin{array}{l}-3.01 \\
(3.52)\end{array}$ & & $\begin{array}{c}0.12 \\
(0.09)\end{array}$ & & $\begin{array}{c}0.08 \\
(0.06)\end{array}$ & & $\begin{array}{l}-0.06 \\
(0.03)+\end{array}$ \\
\hline Observations & 1130 & 1130 & 1135 & 1135 & 1135 & 1135 & 1092 & 1092 \\
\hline R-squared & 0.06 & 0.07 & 0.05 & 0.06 & 0.04 & 0.07 & 0.10 & 0.11 \\
\hline
\end{tabular}

Notes: Each column in each panel represents the result from a separate regression, where the dependent variable is listed as a column heading. All regressions include age dummies, race dummies, a male dummy, and region*urban dummies. The results take into account the complex survey design, including the weights. Standard errors are in parentheses.

+ denotes significance at the 0.10 level; * denotes significance at the 0.05 level; ** denotes significance at the 0.01 level. 
TABLE 6

OLS Regression Results for the 18-64 Age Group

\begin{tabular}{|c|c|c|c|c|c|c|c|c|}
\hline \multirow[b]{2}{*}{ Poverty } & \multicolumn{2}{|c|}{ HEI Score } & \multicolumn{2}{|c|}{ Obesity } & \multicolumn{2}{|c|}{ Low BMI } & \multicolumn{2}{|c|}{ LowSum } \\
\hline & $\begin{array}{l}-2.99 \\
(0.59)^{* *}\end{array}$ & $\begin{array}{l}-2.50 \\
(0.61)^{* *}\end{array}$ & $\begin{array}{c}0.04 \\
(0.02)^{*}\end{array}$ & $\begin{array}{c}0.03 \\
(0.02)+\end{array}$ & $\begin{array}{c}0.00 \\
(0.01)\end{array}$ & $\begin{array}{l}-0.00 \\
(0.01)\end{array}$ & $\begin{array}{l}0.11 \\
(0.02)^{* *}\end{array}$ & $\begin{array}{c}0.09 \\
(0.02) * *\end{array}$ \\
\hline FSfam1 & & $\begin{array}{l}-2.40 \\
(1.03)^{*}\end{array}$ & & $\begin{array}{c}0.00 \\
(0.02)\end{array}$ & & $\begin{array}{c}0.01 \\
(0.01)\end{array}$ & & 0.11 \\
\hline FSself & & $\begin{array}{l}-1.41 \\
(1.11)\end{array}$ & & $\begin{array}{c}0.09 \\
(0.05)+\end{array}$ & & $\begin{array}{c}0.01 \\
(0.02)\end{array}$ & & $\begin{array}{c}0.02 \\
(0.04)\end{array}$ \\
\hline Observations & 11787 & 11787 & 11853 & 11853 & 11853 & 11853 & 11449 & 11449 \\
\hline R-squared & 0.07 & 0.08 & 0.04 & 0.04 & 0.03 & 0.03 & 0.05 & 0.05 \\
\hline Poverty & $\begin{array}{l}-1.66 \\
(0.73)^{*}\end{array}$ & $\begin{array}{l}-1.68 \\
(0.65)^{*}\end{array}$ & $\begin{array}{l}-0.03 \\
(0.03)\end{array}$ & $\begin{array}{l}-0.03 \\
(0.03)\end{array}$ & $\begin{array}{c}0.01 \\
(0.01)\end{array}$ & $\begin{array}{c}0.00 \\
(0.01)\end{array}$ & $\begin{array}{l}0.10 \\
(0.03)^{* *}\end{array}$ & $\begin{array}{c}0.08 \\
(0.04)^{*}\end{array}$ \\
\hline FSfam1 & & $\begin{array}{l}-0.35 \\
(1.65)\end{array}$ & & $\begin{array}{l}-0.04 \\
(0.06)\end{array}$ & & $\begin{array}{c}0.03 \\
(0.03)\end{array}$ & & $\begin{array}{c}0.09 \\
(0.08)\end{array}$ \\
\hline FSfam2 & & $\begin{array}{l}2.48 \\
(1.30)+\end{array}$ & & $\begin{array}{c}0.03 \\
(0.05)\end{array}$ & & $\begin{array}{c}0.01 \\
(0.02)\end{array}$ & & $\begin{array}{l}-0.05 \\
(0.06)\end{array}$ \\
\hline FSfam3 & & $\begin{array}{l}-5.84 \\
(1.57)^{* *}\end{array}$ & & $\begin{array}{l}-0.05 \\
(0.05)\end{array}$ & & $\begin{array}{l}-0.01 \\
(0.02)\end{array}$ & & $\begin{array}{c}0.05 \\
(0.08)\end{array}$ \\
\hline FSself & & $\begin{array}{c}0.48 \\
(1.74)\end{array}$ & & $\begin{array}{c}0.10 \\
(0.05)+\end{array}$ & & $\begin{array}{l}-0.01 \\
(0.01)\end{array}$ & & $\begin{array}{c}0.03 \\
(0.06)\end{array}$ \\
\hline Observations & 3322 & 3322 & 3334 & 3334 & 3334 & 3334 & 3252 & 3252 \\
\hline R-squared & 0.11 & 0.11 & 0.08 & 0.08 & 0.04 & 0.04 & 0.11 & 0.12 \\
\hline
\end{tabular}

Notes: Each column in each panel represents the result from a separate regression, where the dependent variable is listed as a column heading. All regressions include age dummies, race dummies, a male dummy, and region*urban dummies. The results take into account the complex survey design, including the weights. Standard errors are in parentheses.

+ denotes significance at the 0.10 level; * denotes significance at the 0.05 level; ** denotes significance at the 0.01 level. 
TABLE 7

OLS Regression Results for the 65+ Age Group

\begin{tabular}{|c|c|c|c|c|c|c|c|c|}
\hline \multirow[b]{2}{*}{ Poverty } & \multicolumn{2}{|c|}{ HEI Score } & \multicolumn{2}{|c|}{ Obesity } & \multicolumn{2}{|c|}{ Low BMI } & \multicolumn{2}{|c|}{ LowSum } \\
\hline & $\begin{array}{l}-4.09 \\
(0.87)^{* *}\end{array}$ & $\begin{array}{l}-3.73 \\
(0.87)^{* *}\end{array}$ & $\begin{array}{c}0.01 \\
(0.03)\end{array}$ & $\begin{array}{c}0.01 \\
(0.03)\end{array}$ & $\begin{array}{c}0.03 \\
(0.02)\end{array}$ & $\begin{array}{c}0.02 \\
(0.02)\end{array}$ & $\begin{array}{l}0.08 \\
(0.03)^{* *}\end{array}$ & $\begin{array}{c}0.07 \\
(0.03)^{*}\end{array}$ \\
\hline FSfam1 & & $\begin{array}{l}-4.71 \\
(2.59)+\end{array}$ & & $\begin{array}{c}0.04 \\
(0.09)\end{array}$ & & $\begin{array}{c}0.09 \\
(0.05)+\end{array}$ & & $\begin{array}{c}0.16 \\
(0.10)\end{array}$ \\
\hline FSself1 & & $\begin{array}{l}-8.49 \\
(5.21)\end{array}$ & & $\begin{array}{l}-0.09 \\
(0.09)\end{array}$ & & $\begin{array}{c}0.11 \\
(0.09)\end{array}$ & & $\begin{array}{c}0.07 \\
(0.10)\end{array}$ \\
\hline $\begin{array}{l}\text { Observations } \\
\text { R-squared }\end{array}$ & $\begin{array}{r}3262 \\
0.08\end{array}$ & $\begin{array}{r}3262 \\
0.09\end{array}$ & $\begin{array}{r}3330 \\
0.03\end{array}$ & $\begin{array}{r}3330 \\
0.03\end{array}$ & $\begin{array}{r}3330 \\
0.02\end{array}$ & $\begin{array}{r}3330 \\
0.03\end{array}$ & $\begin{array}{r}3227 \\
0.06\end{array}$ & $\begin{array}{r}3227 \\
0.06\end{array}$ \\
\hline Poverty & $\begin{array}{l}-4.33 \\
(1.31)^{* *}\end{array}$ & $\begin{array}{l}-4.00 \\
(1.33)^{* *}\end{array}$ & $\begin{array}{c}0.00 \\
(0.04)\end{array}$ & $\begin{array}{c}0.01 \\
(0.04)\end{array}$ & $\begin{array}{c}0.00 \\
(0.02)\end{array}$ & $\begin{array}{l}-0.01 \\
(0.01)\end{array}$ & $\begin{array}{l}0.12 \\
(0.04)^{* *}\end{array}$ & $\begin{array}{c}0.11 \\
(0.04)^{*}\end{array}$ \\
\hline FSfam1 & & $\begin{array}{l}-7.43 \\
(4.90)\end{array}$ & & $\begin{array}{c}0.08 \\
(0.12)\end{array}$ & & $\begin{array}{c}0.15 \\
(0.09)\end{array}$ & & $\begin{array}{c}0.17 \\
(0.18)\end{array}$ \\
\hline FSfam2 & & $\begin{array}{c}4.26 \\
(4.69)\end{array}$ & & $\begin{array}{l}-0.04 \\
(0.06)\end{array}$ & & $\begin{array}{l}-0.03 \\
(0.03)\end{array}$ & & $\begin{array}{l}-0.05 \\
(0.14)\end{array}$ \\
\hline FSself1 & & $\begin{array}{l}-5.34 \\
(6.36)\end{array}$ & & $\begin{array}{l}-0.12 \\
(0.05)^{*}\end{array}$ & & $\begin{array}{c}0.22 \\
(0.06)^{* *}\end{array}$ & & $\begin{array}{l}-0.00 \\
(0.16)\end{array}$ \\
\hline Observations & 1608 & 1608 & 1632 & 1632 & 1632 & 1632 & 1598 & 1598 \\
\hline R-squared & 0.10 & 0.10 & 0.05 & 0.05 & 0.05 & 0.08 & 0.09 & 0.09 \\
\hline
\end{tabular}

Notes: Each column in each panel represents the result from a separate regression, where the dependent variable is listed as a column heading. All regressions include age dummies, race dummies, a male dummy, and region*urban dummies. The results take into account the complex survey design, including the weights.

+ denotes significance at the 0.10 level; * denotes significance at the 0.05 level; ** denotes significance at the 0.01 level. 
TABLE 8, Panel A

OLS Regression Results by Age Group and Race

\begin{tabular}{|c|c|c|c|c|c|c|c|c|c|}
\hline & \multicolumn{3}{|c|}{ HEI Score } & \multicolumn{3}{|c|}{ Obesity } & \multicolumn{3}{|c|}{ Low Sum } \\
\hline & Black & Hispanic & White/Other & Black & Hispanic & White/Other & Black & Hispsanic & White/OtheI \\
\hline \multicolumn{10}{|l|}{ 2-5 year olds } \\
\hline \multirow[t]{2}{*}{ Poverty } & -3.61 & -2.75 & -0.54 & -0.00 & 0.07 & 0.01 & 0.11 & 0.06 & 0.07 \\
\hline & $(0.71)^{* *}$ & $(1.56)+$ & (1.17) & $(0.02)$ & $(0.04)+$ & $(0.02)$ & $(0.03)^{* *}$ & $(0.04)$ & $(0.05)$ \\
\hline \multirow[t]{2}{*}{ FSfam1 } & -2.10 & 1.94 & 3.36 & -0.02 & -0.07 & 0.03 & -0.01 & 0.01 & -0.05 \\
\hline & $(1.45)$ & $(2.11)$ & $(2.78)$ & $(0.03)$ & $(0.05)$ & $(0.04)$ & $(0.06)$ & $(0.07)$ & $(0.08)$ \\
\hline Observations & 1193 & 1465 & 1207 & 1338 & 1579 & 1331 & 1074 & 1291 & 1013 \\
\hline R-squared & 0.08 & 0.12 & 0.05 & 0.02 & 0.06 & 0.03 & 0.05 & 0.06 & 0.05 \\
\hline \multicolumn{10}{|l|}{ 6-11 year olds } \\
\hline \multirow[t]{2}{*}{ Poverty } & 0.04 & 0.49 & 1.33 & -0.02 & -0.06 & 0.01 & 0.03 & 0.12 & 0.01 \\
\hline & $(0.83)$ & (1.54) & (1.61) & $(0.02)$ & $(0.05)$ & $(0.04)$ & $(0.02)$ & $(0.04)^{* *}$ & $(0.04)$ \\
\hline \multirow[t]{2}{*}{ FSfam1 } & 1.29 & 1.70 & -2.42 & 0.00 & 0.04 & -0.04 & -0.03 & -0.01 & -0.05 \\
\hline & (1.49) & (1.09) & $(1.25)+$ & $(0.05)$ & $(0.04)$ & $(0.06)$ & $(0.06)$ & $(0.05)$ & $(0.07)$ \\
\hline Observations & 1012 & 1078 & 867 & 1061 & 1135 & 907 & 927 & 1037 & 803 \\
\hline R-squared & 0.04 & 0.08 & 0.07 & 0.02 & 0.08 & 0.02 & 0.05 & 0.08 & 0.04 \\
\hline \multicolumn{10}{|c|}{ 12-17 year olds } \\
\hline \multirow[t]{2}{*}{ Poverty } & 0.80 & 2.43 & -1.70 & -0.02 & -0.01 & 0.06 & -0.01 & -0.01 & 0.01 \\
\hline & $(0.78)$ & (1.69) & $(1.70)$ & $(0.02)$ & $(0.06)$ & $(0.06)$ & $(0.04)$ & $(0.03)$ & $(0.06)$ \\
\hline \multirow[t]{2}{*}{ FSfam1 } & -0.90 & -2.66 & -3.30 & -0.04 & -0.09 & 0.04 & -0.01 & 0.02 & 0.04 \\
\hline & (1.98) & $(2.36)$ & $(2.28)$ & $(0.03)$ & $(0.08)$ & $(0.07)$ & $(0.06)$ & $(0.05)$ & $(0.08)$ \\
\hline \multirow[t]{2}{*}{ FSself } & -0.56 & -1.42 & -2.61 & 0.08 & 0.30 & -0.01 & 0.08 & -0.07 & 0.01 \\
\hline & (2.69) & $(2.06)$ & (2.79) & $(0.09)$ & $(0.13) *$ & $(0.06)$ & $(0.10)$ & $(0.11)$ & $(0.07)$ \\
\hline Observations & 755 & 757 & 622 & 759 & 766 & 626 & 704 & 725 & 588 \\
\hline R-squared & 0.03 & 0.10 & 0.05 & 0.03 & 0.13 & 0.02 & 0.17 & 0.16 & 0.14 \\
\hline
\end{tabular}


TABLE 8, Panel B

OLS Regression Results by Age Group and Race

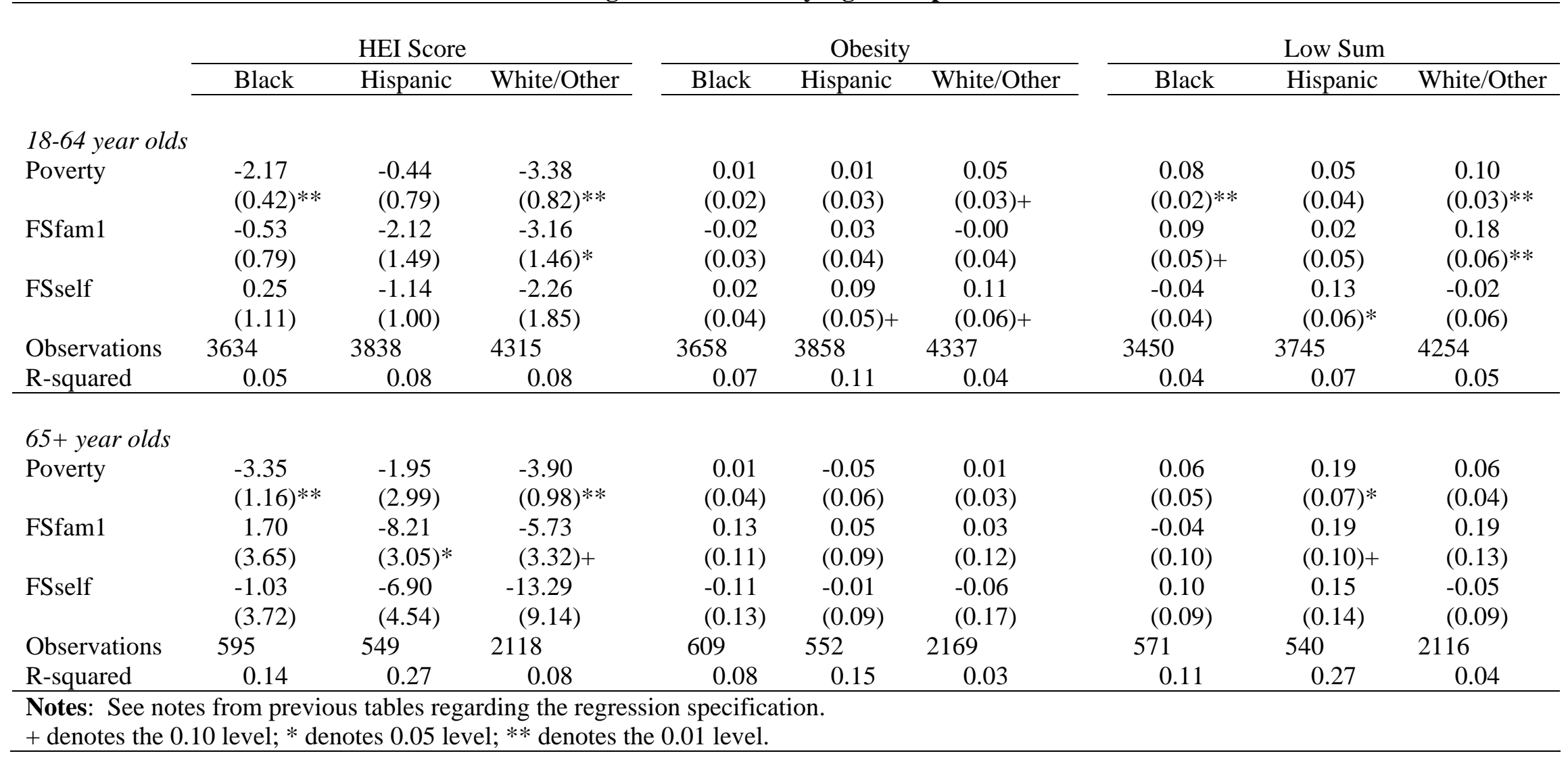

